\title{
An investigation of experiential and transformative learning in study abroad programs
}

\section{Hannah Strange}

Bournemouth University

\section{Heather J. Gibson}

University of Florida

\section{Introduction}

In 2014, the U.S. Department of State announced the creation of a study abroad office, indicating an administrative commitment to increasing the number of outbound US students pursuing international education. Travel has long been thought to provide the stimulation, challenges, and opportunities required for substantive interpersonal and intercultural learning to occur (Vogt, 1976). In the 2014/15 academic year, 313,415 US students studied abroad (Institute of International Education, 2016). This statistic represents a 300\% increase from 1994/95, yet it still represents less than $2 \%$ of US students enrolled in higher education. Additionally, the outcomes of international education are inconclusive. The intercultural goals of study abroad programs are often ill-defined and there is a lack of studies that have measured the outcomes of these programs in a meaningful way (Ritz, 2011; Tarrant, Rubin, \& Stoner, 2014). Simply visiting a different country is not enough to provide real impact (Bell, Gibson, Tarrant, Perry, \& Stoner, 2014; Jackson, 2015). Despite the pervasive philosophy that study abroad learning objectives should go beyond academic content, there has been a lack of attention placed on holistic outcomes for many programs (Pedersen, 2010). For the purpose of this study, holistic outcomes are defined as outcomes which reflect the intellectual, social, and emotional growth of a student (Ritz, 2011). Since study abroad is a substantial commitment and expense for institutions and students alike, it is important to know the effects that various types of programs have on students (Hensley \& Sell, 1979).

Over the past ten years an increasing array of international education experiences have emerged. Program lengths vary from one week to one academic year; they may be exchange programs, located through a provider, or faculty-led; and very little is known about the most appropriate teaching styles for these different types of programs (Hoff, 2005). Prior research has focused almost entirely on the academic outcomes of study abroad (Pedersen, 2010), statistics on participation and satisfaction (McLeod \& Wainright, 2009; Engle \& Engle, 2003), motivation (Barbuto, Beenen, \& Tran, 2015), or the opportunity for students to experience change in their global citizenry (Tarrant, Rubin, \& Stoner, 2014). Subsequently it has been difficult to identify any specific program characteristics that result in more beneficial outcomes for the student and society as a whole. Furthermore, given the wide-ranging areas of study and diverse demands, a one-size-fitsall approach can no longer be justified (Tarrant, Ruben, \& Stoner, 2014). 
Identification of ideal program characteristics has been made more difficult by the lack of studies that examine the potential for short-term programs to have as much impact as traditional long-term programs (e.g. semester long). Traditionally long-term programs have been more academically acceptable since they require greater linguistic and cultural preparation. In semesterlength programs students are more likely to need to assimilate into the host culture and are more likely to be removed from their comfort zone, providing greater opportunity of educational experiences and cultural adaptation (Medina-López-Portillo, 2004; Dwyer, 2004). According to the Institute of International Education Open Doors Project (2016), in the 2015/16 academic year 63\% of US students studying abroad were on programs shorter than eight weeks in length, while traditional year programs comprised only $2 \%$ of the total. This dramatic change in participation makes it imperative to examine the impacts of program length (Chieffo \& Griffiths, 2004), especially since there has been much criticism levied at short-term programs and their ability to provide similar outcomes to longer programs (Anderson, Lawton, Rexeisen, \& Hubbard, 2006; Ritz, 2011).

In investigating program length and student outcomes it is also essential to assess the type of learning environments most conducive to providing particular student outcomes. Tarrant (2010) states that desirable student outcomes of study abroad are ones that encourage students to become more inclusive, discriminating, open, reflective and emotionally able to change, and show higher connectedness to the global environment. A major criticism of study abroad as it stands is the lack of intentionality among programmers. Skelly (2009) argues that we need to ensure that the study abroad industry is teaching to a specific purpose and laying an intellectual foundation for future generations, instead of simply giving in to commodification. In this way we need to design research that evaluates the capacity of study abroad to promote particular outcomes and assess under what conditions this may occur (Tarrant, Rubin, \& Stoner, 2014).

Transformative Learning Theory is a framework proposed by Mezirow (1991). It asserts that through reflection, active learning, and placing ourselves in uncomfortable situations students are able to develop their understanding of the world and of themselves, allowing a potential change to their perspectives and frames of reference. On the other hand Experiential Learning is defined as the type of education whereby knowledge and meaning are contextualized in actual experiences, as often found in study abroad programs (Perry, 2011) The very nature of study abroad involves international travel and experiencing unfamiliar environments, which when combined with effective programming can promote concrete learning. In this way, where students are taken out of their comfort zone in study abroad, this could lead to the uncomfortable situation described by Mezirow (1991) and lead to a learning outcome. Through applying the basis of experiential learning to the potential outcomes of transformative learning, it may be possible to further direct educational programming in study abroad for the better. Since the outcomes of both experiential and transformative learning are in alignment with those desired in study abroad, it is appropriate to use them both as frameworks to assess the effectiveness of a variety of study abroad models.

We suggest that experiential learning can provide guidance on designing study abroad programs to include activities that are "more hands on" and as such is an indicator of program type, whereas transformative learning theory contributes not only to program design, but also to assessing potential outcomes of these international experiences. Thus, the purpose of this study was to investigate the influence of program type (considering experiential components) and length on 
transformative learning outcomes. As such, this study uses transformative learning theory (Mezirow, 1991; 1997; 2003) and experiential learning theory (Kolb, 1984; Kolb \& Kolb, 2005) as combined conceptual frameworks.

\section{Conceptual Framework}

\section{Transformative Learning Theory}

Tarrant (2010) suggested that transformative learning theory (TLT) has the potential to provide the critical framework necessary to test the appropriateness of various program aspects currently popular in study abroad. In transformative learning, Mezirow (1991) asserts that only through reflection, active learning, and placing ourselves in an uncomfortable situation are we fully able to develop our understanding of the world and of ourselves. Transformative learning is achieved when a change occurs to our frame of reference as a result of an event or experience (Mezirow, 1997). We have a subconscious frame of reference which impacts the way we view and interpret the world, thereby driving our actions (Pagano \& Roselle, 2009). Mezirow (2003) explains that where a change occurs to our frame of reference, we can expect to see a subsequent change in action, and this is what is classed as transformative learning.

Mezirow (2003) further suggests that because the strength/intensity of the pre-conceived notions that individuals hold, learning must occur through a four stage process: (1) Elaborate our existing point of view; (2) Establish a new point of view; (3) Transform our point of view, and; (4) Become aware of the world around us and be critically reflective of our environment and actions (Mezirow, 1997). Our ability to change our frame of reference allows us to build professional competencies such as analytical problem solving, planning and organizing, communication, teamwork and global understanding. Mezirow argues that transformative learning encourages us to be more inclusive, self-reflective, and integrative of change, and can promote autonomous and responsible lifelong thinking patterns, empowerment, and a sense of community (Mezirow, 1997; Mezirow \& Taylor, 2011).

Mezirow (1991) further explains that transformative learning can in one way be achieved through a perspective transformation; the process of altering our meaning structures. Meaning structures are culturally acquired subconscious perspectives that build our frame of reference. He proposes that any change in these meaning structures is achieved through a ten-stage process: (1) Experience a disorienting dilemma; (2) Self-examine and feel guilt or shame about your perspective; (3) Critically assess your assumptions; (4) Recognize that these changes occur in others; (5) Explore options for a new perspective; (6) Plan new actions; (7) Acquire new skills; (8) Provisionally attempt a new frame of mind; (9) Build competence in new ideas; and (10) Fully reintegrate into life. It is important to note here that while it states it is necessary for students to experience guilt or shame in order to achieve a perspective transformation, this is a specific tenet of achieving perspective transformation, which is a particular type of transformative learning. Mezirow (1997) discusses in other readings other ways in which transformative learning can be achieved without experiencing negative emotions, but these are not aspects of transformative learning being used in this study.

When applied to international education, an overreaching goal of transformative learning is to move students from perspectives that have allowed ethnocentrism and dualistic epistemologies and allow the creation of a new frame of reference that promotes cultural pluralism (Berwick \& Whalley, 
2000). It is possible that this can be achieved in short-term study abroad experiences when strong academic content and the geographic dimensions are combined (Bell et al., 2014). In the context of study abroad, Taylor (1998) suggests that transformative learning can be achieved through a perspective transformation. He goes on to suggest that when students experience a perspective transformation, their new meaning structures become more inclusive, differentiating, permeable, critically reflective and integrative of experience.

\section{Experiential Learning Theory}

While the TLT focuses on the processes involved in changing an individual's frames of reference, Experiential Learning Theory (ELT) provides direction as to how we can develop the type of action oriented experience that is likely to induce transformation. Experiential learning theory (ELT) is used widely through the study abroad literature and was originally developed by Kolb in 1971. ELT draws from $20^{\text {th }}$ century scholars who placed emphasis on human experience in their theories of development and learning, notably John Dewey, Kurt Lewin, and Jean Piaget (Kolb \& Kolb, 2005). Kolb (1984) noted that there are six principles shared amongst these scholars that combined to create ELT. These principles are as follows: (1) Learning should not be considered an outcome, but as a process; (2) learning is a continual process grounded through experience; (3) learning requires resolution of conflicts between modes of adaptation to the world; (4) learning is a process of holistic adaptation to the world; (5) learning comprises interactions between the person and environment; and (6) learning is the process of creating knowledge.

From this collection of principles, Kolb and Kolb (2005) suggest that ELT "is a holistic model of the experiential learning process and a multi-linear model of adult development" (p. 194). As its core principle, ELT defines learning as the process in which knowledge is created through the transformation of experiences (Kolb, 1984). Experiential Learning can be achieved through concrete experience, abstract conceptualization, reflective observation, and active experimentation. Through touching all of these bases, knowledge is constructed and learning achieved (Kolb \& Kolb, 2005).

Experiential learning associated with study abroad can make a considerable impact on a students' ability to understand globally complex problems (Kiely, 2004). While study abroad usually involves some form of active learning, this does not always lead to experiential learning as some programs do not allow students critical time for interaction and reflection (Aguilar \& Gingerich, 2002). Montrose (2002) explains that there is little understanding among providers and administrators of what exactly constitutes experiential learning and how it can be applied to improve program structure. Experiential learning has the potential to play a critical role in the values and behaviors that students take from study abroad programs, making it essential that programmers fully consider the potential holistic outcomes of their programs and how they are best achieved (Tarrant, 2010; Ritz, 2011). While all study abroad has the potential to provide experiential learning, unmonitored study abroad experiences can be 'mis'-educative, based on the idea that all types of education will have some type of impact and that no form of education is neutral (Aguilar \& Gingerich, 2002, p. 46).

McKeown (2009) explains that many programs lack structure including faculty-student engagement, group discourse, and reflective exercises. Aguilar and Gingerich (2002) further state that reflection, critical analysis, and synthesis are essential elements if programs are to reach their 
potential. Tarrant (2010) agrees by stating that where programs, even short-term ones, are experientially structured, there is a high propensity that students will achieve a new worldview by the end of the program. Aguilar and Gingerich (2002) argue that a key advantage of the study abroad medium is that by its nature it presents the opportunity for students to test recently understood concepts on their lived experiences, providing a more grounded method for acquiring knowledge. They further discuss that study abroad and experiential education are natural partners, while one does not necessarily indicate the other, they both intend to empower students and embrace the notion of education being achieved through social transformation.

Program Length and Links to Experiential Learning and Transformation

In addition to the design of study abroad programs in terms of the degree of their experiential learning and potential for transformative learning, another design element that has been a focus of recent debate is program length (Anderson, Lorenz, \& White, 2016; Barkin, 2016). Short-term programs have frequently been criticized for many reasons including requiring little input on behalf of the student and not producing the same cultural outcomes as longer programs since they do not provide adequate time for student attitudes to change (Engle \& Engle, 2003; Gadykunst, 1979; Medina-López-Portillo, 2004). There has also been critique of short-term programs' ability to increase cultural sensitivity and provide holistic growth on the same level as long-term programs (Anderson et al., 2006). Other criticism suggests that institutions are treating international education as a numbers game, taking students away from the home institution for as little time as possible (Engle \& Engle, 2003). In this way, institutions are able to maximize profits from students, while still maintaining high percentages of students studying abroad. Engle and Engle go on to say that criticism of this kind has led to the suggestion that trips less than six weeks in length should be titled as field trips not as study abroad since it is argued that they cannot integrate a full educational experience into such short travel-oriented programs.

While many believe that an extensive duration is instrumental in achieving outcomes, there has also been considerable argument that short-term programs can have similar impacts to the more traditional longer programs (Anderson et al., 2006). Anderson et al. found that in a group of study abroad students there was a considerable increase in their intercultural sensitivity despite only participating in a four-week program. Dwyer (2004) elaborates by stating that short-term programs where they are well-planned and intensive in nature can have a considerable impact on students, especially if they exceed the critical six-week mark. Medina-López Portillo (2004) concurs by stating that regardless of length, students are only seeing the proverbial tip of the iceberg in terms of deep cultural understanding.

Other research indicates that short-term programs afford students the opportunity to participate in multiple programs across the course of their degree, enabling participants to experience several worldviews (Chieffo \& Griffiths, 2004). Given the extensive demands on current undergraduates, it is possible that short-term programs are the only realistic option for many students, particularly as Tarrant, Ruben, \& Stoner (2014) explain if we wish to achieve democratization and diversification of study abroad. Where short-term programs are intensely and pedagogically designed, they can have as significant an impact as long-term programs (Ritz, 2011). Bell and Anscombe (2013) concur, stating that where there is appropriate academic preparation, ongoing facilitation, purposeful program design, and adequate opportunity for guided reflection and 
discussion, short-term study abroad can be successful. Collectively this indicates that a focus on not only length, but also on quality of programming is now necessary. As such the degree to which programs are structured with transformative learning in mind, and incorporate an experiential education approach, can be used as a measure to assess the influence of program type on student learning outcomes.

Thus, the purpose of this study was to investigate the transformative learning potential of university level study abroad programs and to assess the influence of experiential learning components (operationalized as program type) and program length on transformative learning. Specifically, the following research questions were addressed:

1. Does transformative learning occur on study abroad programs?

2. Does transformative learning differ by program length?

3. Does transformative learning differ by degree of experiential learning offered (i.e., program type)?

\section{Method}

\section{Data Collection}

An online survey design was used to collect data from college students enrolled in 2012 summer study abroad programs through a large south-eastern US university. These programs included faculty-led study abroad and exchange programs ranging from one-week to one semester in length. Approximately 950 students were asked to participate. After initial contact at pre-departure sessions, the researcher contacted the student participants via email post-trip, reminding them about the study, and providing the URL link to the survey. The protocol was reviewed by the Institutional Review Board at the University and approved for the inclusion of human subjects. All data and analysis were conducted in accordance with the approved protocol.

\section{Instrument}

The instrument consisted of a fixed-choice and open-ended response format questionnaire containing three sections. Section one used the learning activities survey questionnaire originally developed and validated by King (1998) as used in Brock's (2010) test of transformative learning. The precursor steps of transformative learning outlined by Mezirow (1997) were operationalized by Brock into a yes $=1 / \mathrm{no}=0$ question format. For instance, step one 'a disorienting dilemma' was measured by the statements "I had an experience that caused me to question the way I normally act," and "I had an experience that caused me to question my ideas about social roles." Each item was similarly operationalized and was answered in a yes/no format. The rest of the ten steps were operationalized as follows: Step two "as I questioned my ideas, I realized I no longer agreed with my previous beliefs or role expectations" and/or instead, "as I questioned my ideas, I realized I still agreed with my beliefs or role expectations;" step three "I realized that other people also questioned their beliefs;" step four "I thought about acting in a different way from my usual beliefs and roles;" step five "I felt uncomfortable with traditional social expectations;" step six "I tried out new roles so that I would become more comfortable or confident in them;" step seven "I tried to figure out a way to adopt these new ways of acting;" step eight "I gathered the information I needed to adopt 
these new ways of acting;" step nine "I began to think about reactions and feedback from my new behaviour;" and step ten "I took action and adopted these new ways of acting."

Section two comprised items pertaining to experiential learning and program type. Participants were asked to select which class components applied to their program and answered open-ended questions regarding program components for example "Did the components in your program impact your learning? How?" Section three measured demographic information including gender, age and class standing among other indicators. The internal consistency of the transformative learning scale was established using Cronbach's alpha $(\alpha=.80)$. This is consistent with King's (1998) test of the learning activities survey $(\alpha=.86)$. The instrument's reliability and validity have been repeatedly confirmed through the use of multiple data sources, member checks, and independent coding (Brock, 2010; King, 1997, 1998, 1999, 2000, 2003, 2009).

\section{Sample}

The study yielded $n=216$ responses, constituting a $22.74 \%$ response rate, although due to an on-line survey platform error the workable sample for some of the analyses were based on $\mathrm{n}=126$. Of the participants in the sample who provided demographic information, $77.8 \%$ were females $(n=$ $98)$ and $22.2 \%$ were males $(n=28), 72.8 \%(n=91)$ were aged $18-21$ years, $30.2 \%(n=38)$ were juniors, $32.5 \%(n=41)$ were seniors, $69.8 \%(n=88)$ were White/Caucasian, and $91.1 \%(n=113)$ reported American citizenship. Programs ranged in length from six days to 180 days $(M=41.79$ days, $S D=26.89$ days). Length was categorized into short (0-18 days, $n=19)$, medium (19-35 days, $n=45)$, long (36-49 days, $n=36)$, and extra-long programs $(50+$ days, $n=25)$. Program type was assigned by the students into traditional classes $15.1 \%(n=19)$, combination $45.2 \%(n=57)$, field or practical $3 \%(n=29)$, and other $16.7 \%(n=21)$.

\section{Data Analysis}

Data were analyzed using SPSS (Statistical Package for the Social Sciences). Descriptive statistics were generated for all the variables and included means, frequencies, percentages and standard deviations. ANOVA (analysis of variance test to analyze the differences among group means) was used to analyze differences in transformative learning experiences on program length. Nominal level data were summed to measure transformative learning via the twelve dichotomous items. The open ended data were subjected to a thematic analysis. This was conducted manually by the lead researcher. Data were initially coded into categories and then cross-referenced identifying similarities and differences across the codes. The responses were evaluated according to dimensions of experiential and transformative learning and reported by theme and sub-theme.

\section{Results}

In measuring transformative learning, students answered yes $=1$ or no $=0$ to each of the twelve items operationalized by Brock (2010). Item 1 received the most positive responses and items 3, 9, 6 and 10 also received high levels of positive responses (Table 1). The fewest positive responses were to item 7 . Twenty-nine participants $(n=13.8 \%)$ responded yes to ten of the transformative scale items $(13.8 \%)$. Only five students $(n=2.4 \%)$ did not respond positively to any of the scale items, $58.1 \%$ responded positively to six or more items. Each indication of 'yes' was added to create a summed score out of twelve. The responses ranged from a low score of 0 , to a high score of 12 $(\mathrm{M}=6.91, \mathrm{SD}=3.22)$. 
Table 1. Frequency of 'yes' responses to transformative scale items.

\begin{tabular}{|c|c|c|c|c|}
\hline $\begin{array}{l}\text { Ranked } \\
\text { Transformative } \\
\text { learning step \# }\end{array}$ & Item description & Frequency 'Yes' & Valid Percent & Total $(\mathbf{N})$ \\
\hline 1 & $\begin{array}{l}\text { I had an experience that caused me to } \\
\text { question the way I normally act }\end{array}$ & 145 & 67.1 & 216 \\
\hline 3 & $\begin{array}{l}\text { As I questioned my ideas, I realized I } \\
\text { still agreed with my beliefs or role } \\
\text { expectations }\end{array}$ & 143 & 66.5 & 215 \\
\hline 9 & $\begin{array}{l}\text { I tried to figure out a way to adopt } \\
\text { new roles, or new ways of acting }\end{array}$ & 141 & 65.6 & 215 \\
\hline 6 & $\begin{array}{l}\text { I thought about acting in a different } \\
\text { way from my usual beliefs and roles }\end{array}$ & 140 & 64.8 & 216 \\
\hline 10 & $\begin{array}{l}\text { I gathered information I needed to } \\
\text { adopt new ways of acting }\end{array}$ & 140 & 65.7 & 213 \\
\hline 2 & $\begin{array}{l}\text { I had an experience that caused me to } \\
\text { question my ideas about social roles }\end{array}$ & 139 & 64.4 & 216 \\
\hline 11 & $\begin{array}{l}\text { I began to think about reactions to my } \\
\text { new behavior }\end{array}$ & 137 & 63.7 & 215 \\
\hline 8 & $\begin{array}{l}\text { I tried out new roles so that I would } \\
\text { become more comfortable in them }\end{array}$ & 128 & 59.3 & 216 \\
\hline 12 & $\begin{array}{l}\text { I adopted these new ways of thinking } \\
\text { and acting }\end{array}$ & 127 & 59.3 & 214 \\
\hline 5 & $\begin{array}{l}\text { I realized that other students were also } \\
\text { questioning their beliefs }\end{array}$ & 122 & 56.7 & 215 \\
\hline 4 & $\begin{array}{l}\text { As I questioned my ideas I realized I } \\
\text { no longer agreed with my beliefs or } \\
\text { role expectations }\end{array}$ & 52 & 24.1 & 216 \\
\hline 7 & $\begin{array}{l}\text { I felt uncomfortable with traditional } \\
\text { social expectations }\end{array}$ & 50 & 23.3 & 215 \\
\hline
\end{tabular}

Respondents reported program length in days and these were categorized into four groups. Short programs comprised $0-18$ days $(15.2 \%, n=19)$, medium $19-35$ days $(36 \%, n=45)$, long 36-49 days $(28.8 \%, n=36)$, and extra-long $50+$ days $(20 \%, n=25)$. The groups were categorized according to previous literature and the distribution of the program length variable. The shortest reported length was six days; the longest was 180 days. 
Table 2. One-way ANOVA testing difference in transformative learning by program length.

\begin{tabular}{|c|c|c|c|c|c|c|c|c|}
\hline $\begin{array}{l}\text { Program Length } \\
\text { (days) }\end{array}$ & $\mathbf{N}$ & Mean* & SD & Df & Sum of Squares & $\begin{array}{l}\text { Mean } \\
\text { Square }\end{array}$ & $\mathbf{F}$ & $\mathbf{p}$ \\
\hline Short (0-18) & 19 & 4.29 & 3.24 & & & & & \\
\hline Medium (19-35) & 45 & 7.09 & 3.12 & & & & & \\
\hline Long (36-49) & 36 & 7.26 & 2.78 & & & & & \\
\hline Extra-Long $(50+)$ & 25 & 7.92 & 3.19 & & & & & \\
\hline Between Groups & & & & 3 & 146.37 & 48.79 & 5.21 & 0.002 \\
\hline Within Groups & & & & 116 & 1085.63 & 9.36 & & \\
\hline Total & 120 & 6.91 & 3.22 & 119 & 1231.99 & & .034 & \\
\hline
\end{tabular}

*Transformative learning total score ranging from $0-12$

ANOVA was used to explore differences among program length categories and the transformative learning experienced by the participants. Table 2 shows the mean transformative learning sum for each group. A one-way ANOVA showed a statistical significance $(p<.01)$ between program length and the summated transformative learning score (Table 2). A Tukey post hoc analysis (Table 3) indicated that there was a significant difference in transformative learning achieved between the 'short' program group (0-18 days) and the medium (19-35 days), long (36-49 days), and extra-long $(50+$ days $)$ groups respectively $(\not(a) l)<.01)$. The mean transformative learning score for the short program group $(M=4.29)$ was significantly lower than that of the medium $(M=7.09)$, long $(\mathrm{M}=7.26)$, and extra-long $(\mathrm{M}=7.92)$ groups, indicating that a higher degree of transformative learning occurred on the medium, long, and extra-long programs in comparison to the shortest programs.

Table 3. Tukey post hoc results for program length in relation to transformative learning

\begin{tabular}{llll}
\hline Tukey HSD & Length Category & Length Category & Sig. \\
\hline Short (0-18 days) & Medium & $0.009^{*}$ \\
& Long & $0.008^{*}$ \\
& Extra Long & $0.002^{*}$ \\
& Short & $0.009^{*}$ \\
& Long (36-49 days) & Extra Long & 0.99 \\
& Short & 0.71 \\
& Medium & $0.008^{*}$ \\
& Extra Long & 0.99 \\
Extra Long (50+ days) & Short & 0.86 \\
& Medium & $0.002^{*}$ \\
& Long & 0.71 \\
& &
\end{tabular}

*Indicates a significant difference 
Students were asked to indicate which of 16 learning components they had experienced on their programs (Table 4). A one-way ANOVA was used to investigate the differences between program types and degree of transformative learning experienced (Table 5). Participants selfreported the type of program into four categories; traditional classes $(15.1 \%, n=19, N=126)$, field or practical $(23 \%, n=29)$, combination $(45.2 \%, n=57)$, and other $(16.7 \%, n=21)$. There was no statistical difference $(p=.47)$ among program type and the summated transformative learning score. The mean transformative learning summative scores for each group were as follows; traditional classes $(M=5.94, S D=3.21)$, Combination $(M=7.16, S D=3.25)$, Field or practical $(M=6.7, S D$ $=3.59)$, and other $(M=7.38, S D=2.5)$. While there were no statistically significant findings among the groups, by looking at the mean transformative learning scores it is possible to see that there were incremental differences. Traditional classes received the lowest mean score, followed by the field or practical group, then combination type, with the 'other' category showing the highest propensity of transformative learning.

Table 4. Frequencies of learning components experienced by students while on study abroad.

\begin{tabular}{lll}
\hline Learning component & Frequency (N=126) & Valid percent \\
\hline Formal quiz & 37 & 17.1 \\
Field quiz & 7 & 3.2 \\
Multiple choice exam & 35 & 16.2 \\
Short answer exam & 52 & 24.1 \\
Essay exam & 31 & 14.4 \\
Open-book exam & 16 & 7.4 \\
Debate & 35 & 16.2 \\
Group project & 70 & 32.4 \\
Student discussion & 62 & 28.7 \\
Field lecture & 60 & 27.8 \\
Field trip & 107 & 49.5 \\
Presentation & 90 & 37 \\
Experiment & 96 & 5.1 \\
Interaction with local community as part & 80 & \\
of program & & 37 \\
Interaction with local community as & & \\
leisure time & & \\
Other & & \\
\hline
\end{tabular}


Table 5. One-way ANOVA testing difference in transformative learning among program types.

\begin{tabular}{|c|c|c|c|c|c|c|c|c|}
\hline Program Type & $\mathbf{N}$ & Mean* & SD & Df & $\begin{array}{l}\text { Sum of } \\
\text { Squares }\end{array}$ & $\begin{array}{l}\text { Mean } \\
\text { Square }\end{array}$ & $\mathbf{F}$ & $\mathbf{p}$ \\
\hline Traditional Classes & 19 & 5.94 & 3.21 & & & & & \\
\hline Combination & 57 & 7.16 & 3.25 & & & & & \\
\hline Field or practical & 29 & 6.7 & 3.59 & & & & & \\
\hline Other & 21 & 7.38 & 2.5 & & & & & \\
\hline Between Groups & & & & 3 & 26.12 & 8.71 & 0.84 & 0.47 \\
\hline Within Groups & & & & 117 & 1207.05 & 10.32 & & \\
\hline Total & 126 & 6.92 & 3.21 & 120 & 1233.17 & & & 0.19 \\
\hline
\end{tabular}

*Transformative learning total score ranging from 0-12

\section{Open-ended Questions}

Students responded to open-ended questions regarding transformative learning experiences, the length of their program, and experiential learning aspects. When asked 'During your study abroad did you experience a situation that changed your beliefs or values?' Sixty-five students responded that they had experienced a change in their beliefs or value system. Students' responses covered themes such as understanding the United States, changing their value systems, global outlook, career and personal goals, and travel aspirations.

Students were also asked 'Do you feel that your study abroad program length was adequate to meet your goals?' Approximately two-thirds of students stated that they were happy with the length of their program, with only one student stating that it was a bit long for me because I had such a difficult time feeling at place (sic).' Students who were happy with the length of their program reported that 'I think six weeks is perfect time for the summer,' 'my program was short enough (two weeks) that I was able to feel comfortable communicating upon return,' and 'I think any less than eight weeks would have been futile.' Though many students also expressed a desire to be there for longer, one 20-year old female who studied in France and Germany suggested that 'it's not a matter of the length of time, rather on the experiences had and the bonds formed' and this was a common theme throughout the comments.

When asked about how components of their program affected their learning, none of the students suggested that the 'typical' learning tools such as lectures, quizzes, and multiple choice exams were the most useful aspect of their study abroad. One 20 -year-old female stated that it was just like a normal class, I would have liked more interaction with the local community as a part of the program.' Where experiential elements were missing, the students picked up on this and made statements such as 'I would have preferred to go on more field trips and interact more with Italians.'

Approximately half of the responses reported that the field trips and interactions with the community were the most influential aspects of their program, making comments like 'tours of public hospitals had the most impact,' and 'all of the experiential learning was amazing because all the book knowledge that we had been gaining in a traditional school setting was more or less 
abandoned, and instead we concentrated on how we as individuals were impacted by our interactions with our peers, local and native Australians, and the land.'

\section{Discussion}

In his definition of transformative learning Mezirow (1978) suggested that only through reflection, active learning and placing individuals in uncomfortable situations are they able to develop an understanding of the world and others, thereby achieving transformation. The quantitative data show that almost all of the students achieved some level of transformative learning with some reporting that they had achieved what Mezirow (1991) terms a full perspective transformation. In the responses to the open-ended questions, there was evidence that the participants showed signs of achieving all three of the basic pre-cursors to transformative learning. These responses also show that the students are aware that the experiential nature of their programs is more meaningful for them (Bell et al., 2014).

In terms of the influence of program length on cultural and transformative outcomes, where a program was less than 18 days long, a significantly lower chance of achieving transformative learning was found. This is a considerably lower program length than previous studies have shown (Engle \& Engle, 2003; Dwyer, 2004; Ritz, 2011). Programs less than four or six weeks in length have previously been criticized for lack of academic impact (Engle \& Engle, 2003), this study shows that it may be possible for programs in the three to six week range to have just as great of an impact as those a full semester, or academic year long. The results of this study support the idea that there appears to be little difference in the transformative educational ability of programs based on program length, providing they are more than 18 days in length.

Previous literature suggests that where short-term programs are well-planned and intensive (Bell \& Anscombe, 2013), and have a positive social connection between students and professors (Ritz, 2011), they can have a similar impact on students as long-term programs (Chieffo \& Griffiths, 2004). The open-ended data showed that some students encountered intensively reflective programs that incorporated a lot of different learning elements. Similarly, some participants reported an appreciation for traveling with professors; signifying a key factor of transformative learning where the professor acts as a guide, not instructor (Aguilar \& Gingerich, 2002). If the trend of increasingly more students opting to participate in short-term programs continues, it may be useful for study abroad providers to more directly address the type of learning elements they are using, and how to best encourage student transformation (Tarrant, 2010). These results may stimulate discussion suggesting that short-term programs, provided they are more than 18 days long, may have as great of an impact on students as traditional long term study abroad programs.

When analyzing the data it was posited that higher degrees of experiential learning components could increase the likelihood of students experiencing a perspective transformation, however the quantitative data showed that there were no significant differences in transformative learning among the different types of program. Though this may seem conclusive, the research design was limited by students self-reporting their program type, and the sample sizes. While the quantitative data does not support our proposal, the open-ended responses support the existence of experiential learning components in these study abroad programs, and further directs that they had an impact on the perspective transformation in students. Many students made statements that indicated 
transformative learning stages were accomplished as a result of the experiential learning components. A majority of respondents indicated that the most influential parts of their programs were the field trips, self-reflection, community interaction, and writing aspects. These components and the ability to have concrete experiences, reflective observations, and active experimentation are key tenets of Experiential Learning Theory (Kolb \& Kolb, 2005). Students indicated that they were not only being given the opportunity for active learning, but also the ability to reflect on their experiences through essays and in-depth student-led class discussions, ultimately showing that a relationship may exist between experiential learning components and the achievement of a perspective transformation. This finding warrants more research since if it can be quantitatively supported. In the future programs can be designed with structured experiential components in mind in order to foster the likelihood of students achieving a perspective transformation, and this would be an excellent application to study abroad programming and design.

This study may be a starting point in examining the impact of length and program type on transformative learning. There are some limitations that need to be acknowledged. Limitations included the operationalization of the experiential learning variable. Allowing students to self-report program type may not have adequately identified the degree of experiential learning in each program, limiting the usefulness of this variable. Additionally, the operationalization of a perspective transformation by Mezirow (1991) may suggest that transformative learning can only be achieved if negative emotions such as shame and guilt are felt. While in his other writings (Mezirow, 1997) he suggests that there are other methods to achieve transformative learning, the instrument used in this study does not address these alternative ways, and as such this can be considered a limitation of the framework in how it was applied to this study. Finally, due to an error with the online data collection software, while the sample as a whole was $\mathrm{N}=216$, much of the data from the second and third sections of the questionnaire was based on only $\mathrm{N}=126$. This may have compromised the stability of the analysis with some of the independent variables.

This study is delimited to students who were registered to study abroad with the university during summer 2012. This limited the generalizability of the results to those studying abroad for no more than three months, excluding those who study abroad for a full academic year. The findings may only be generalized to institutions comparable to the host institution and programs of three months or less.

This study made some progress in combining conceptual frameworks from higher education and study abroad literatures. Considering the changes within international education and the possible impact on students' careers and personal lives, it is pertinent for research to continue. Given the potential to see a more defined relationship between experiential learning components and transformative learning, it is suggested that a syllabus and itinerary analysis might better identify the influence of experiential components on transformative learning. It is recommended that future studies obtain information from program directors/faculty enabling the researcher to understand some of the logistics and issues impacting program delivery, allowing a triangulation process. Though transformative learning, experiential learning, and length have all been discussed within the study abroad literature before, this is the first time they have been combined in one study. It is recommended that future studies examine the interactive effects of these variables. 


\section{References}

Aguilar, A. L., \& Gingerich, O. (2002). Experiential pedagogy for study abroad: Educating for global citizenship. Frontiers: The Interdisciplinary Journal of Study Abroad, 8, 41-82.

Anderson, P., Lawton, L., Rexeisen, R., \& Hubbard, A. (2006). Short-term study abroad and intercultural sensitivity: A pilot study. International Journal of Intercultural Relations, 30, 457-469.

Anderson, C., Lorenz, K., \& White, M. (2016). Instructor Influence on Student Intercultural Gains and

Learning during Instructor-Led, Short-Term Study Abroad. Frontiers: The Interdisciplinary Journal of

Study Abroad, 28, 1-23.

Barbuto, J. E., Beenen, G., \& Tran, H. (2015). The role of core self-evaluation, ethnocentrism, and cultural intelligence in study abroad success. The International Journal of Management Education, $13,268-277$.

Barkin, G. (2016). Undergraduate Research on Short-Term, Faculty-Led Study Abroad. Council on Undergraduate Research, 36(4), 26-33.

Bell, H., Gibson, H., Tarrant, M., Perry, L., \& Stoner, L. (2014). Transformational learning through study abroad: US students' reflections on learning about sustainability in the South Pacific. Leisure Studies, DOI:10.1080/02614367.2014.962585

Bell, K., \& Anscombe, W. (2013). International Field Experience in Social Work: Outcomes of a short term study abroad programme to India. Social Work Education: The International Journal, 32 (8), 1032-1047.

Berwick, R. F., \& Whalley, T. R. (2000). The experiential bases of culture learning: A case study of Canadian high schoolers in Japan. International Journal of Intercultural Relations, 24, 325-340

Brock, S. E. (2010). Measuring the importance of precursor steps to transformative learning. Adult Education Quarterly, 60(2), 122-142

Brown, L. (2009). The transformative power of the international sojourn. Annals of Tourism Research, $36(3), 502-521$.

Chieffo, L., \& Griffiths, L. (2004). Large-scale assessment of student attitudes after a short-term study abroad program. Frontiers: The Interdisciplinary Journal of Study Abroad, 10, 165-177.

Dwyer, M. (2004). More is better: The impact of study abroad program duration. Frontiers: The Interdisciplinary Journal of Study Abroad, 10, 151-163.

Engle, L., \& Engle, J. (2003). Study abroad levels: Toward a classification of program types. Frontiers: The Interdisciplinary Journal of Study Abroad, 9, 1-20.

Gudykunst, W. B. (1979). The effects of an intercultural communication workshop on cross- cultural attitudes and interaction. Communication Education, 28(3), 179.

Hamad, R., \& Lee, C. (2013). An assessment of how length of study-abroad programs influences crosscultural adaptation. Journal of Human Behavior in the Social Environment, 23(5), 661-674.

Hensley, T., \& Sell, D. (1979). A study-abroad program: "An examination of impacts on student attitudes". Teaching Political Science, 6(4), 387-411.

Hoff, J. G. (2005). Students' perceptions of the culture learning process during the study abroad experience. (Unpublished doctoral dissertation). University of Minnesota, Minneapolis, MN.

Institute of International Education (2016). Open Doors: Report on international educational exchange. Retrieved January 25, 2017, from http://www.iie.org/en/Research-and-Publications/OpenDoors/Data/Fast-Facts

Jackson, J. (2015). Becoming interculturally competent: Theory to practice in international education. International Journal of Intercultural Relations, 48, 91-107.

Kiely, R. (2004). A chameleon with a complex: Searching for transformation in international servicelearning. Michigan Journal of Community Service Learning, 10(2), 1-17.

Kiely, R. (2005). A transformative learning model for service-learning: a longitudinal case study. Michigan Journal of Community Service Learning, 12(1), 1-17.

King, K. P. (1997). Examining Activities that Promote Perspective Transformation among Adult Learners in Higher Education. International Journal of University Adult Education, 36(3), 23-37. 
King, K. P. (1998). A guide to perspective transformation and learning activities: The learning activities survey. Philadelphia: Research for Better Schools.

King K. P. (1999). Unleashing technology in the classroom: What adult basic education teachers and organizations need to know. Adult Basic Education, 9, 162-175

King K. P. (2000). The adult ESL experience: Facilitating perspective transformation in the classroom. Adult Basic Education, 10, 69-89.

King K. P. (2003). Understanding adult learners amidst societal crisis: Learning and grief in tandem. Journal of Continuing and Higher Education, 51, 13-23

King K. P. (2004). Both sides now: Examining transformative learning and professional development of educators. Innovative Higher Education, 29, 155-174.

King, K. P. (2009). The handbook of the evolving research of transformative learning based on the Learning Activities Survey. Charlotte, NC: Lap-information Age Pub. Incorporated.

Kolb, D. A. 1984. Experiential learning: Experience as the source of learning and development. Upper Saddle River, NJ: Prentice-Hall.

Kolb, A., \& Kolb, D. (2005). Learning styles and learning spaces: Enhancing experiential learning in higher education. Academy of Management and Learning Education, 4(2), 193-212.

McKeown, J. S. (2009). The first time effect: the impact of study abroad on college student intellectual development. Albany, NY: State University of New York Press.

McLeod, M., \& Wainright, P. (2009). Researching the study abroad experience. Journal of Studies in International Education, 13(1), 66-71.

Mapp, S. (2012). Effect of short-term study abroad programs on students' cultural adaptability. Journal of Social Work Education, 48 (4), 727-737.

Medina-López-Portillo, A. (2004). Intercultural learning assessment: The link between program duration and the development of intercultural sensitivity. Frontiers: The Interdisciplinary Journal of Study Abroad, 10, 179-199.

Mezirow, J. (1978). Perspective Transformation. Adult Education Quarterly, 28(2), 100-110.

Mezirow, J. (1991). Transformative dimensions of adult learning. San Francisco: Jossey-Bass.

Mezirow, J. (1997). Transformative learning: Theory to practice. New Directions for Adult and Continuing Education, 74, 5-12.

Mezirow, J. (2003). Transformative learning as discourse. Journal of Transformative Education, 1(1), 5863.

Mezirow, J. (2011). Transformative learning in practice: Insights from community, workplace, and higher education. San Francisco, CA: John Wiley \& Sons.

Mezirow, J., \& Taylor, E. W. (2011). Transformative learning in practice: Insights from community, workplace, and higher education. San Francisco, CA: John Wiley \& Sons.

Montrose, L. (2002). International study and experiential learning: The academic context. Frontiers: The Interdisciplinary Journal of Study Abroad, 8, 1-15.

Pagano, M., \& Roselle, L. (2009). Beyond reflection through an academic lens: Refraction and international experiential education. Frontiers: The Interdisciplinary Journal of Study Abroad, 18, 217-229.

Pedersen, P. (2010). Assessing intercultural effectiveness outcomes in a year-long study abroad program. International Journal of Intercultural Relations, 34, 70-80.

Perry, L. G. (2011). A naturalistic inquiry of service-learning in New Zealand university classrooms: determining and illuminating the influence on student engagement: a thesis presented to the Faculty of the College of Education, University of Canterbury, in partial fulfillment of the requirements for the degree of Doctor of Philosophy. University of Canterbury.

Ritz, A. (2011). The educational value of short-term study abroad programs as course components. Journal of Teaching in Travel \& Tourism, 11(2), 164-178.

Schattle, H. (2009). Global citizenship in theory and practice. The Handbook of Practice and Research in Study Abroad: Higher Education and the Quest for Global Citizenship, (Ed.) Ross Lewin (3-20). New York, NY: Routledge. 
Skelly, J. M. (2009). Fostering Engagement. The Handbook of Practice and Research in Study Abroad: Higher Education and the Quest for Global Citizenship, (Ed.) Ross Lewin (21-32). New York, NY: Routledge.

Tarrant, M. (2010). A conceptual framework for exploring the role of studies abroad in nurturing global citizenship. Journal of Studies in International Education, 14(5), 433-451.

Tarrant, M. (2014). The added value of study abroad: Fostering a global citizenry. Journal of Studies in International Education, 18(2), 141-161.

Tarrant, M., Rubin, D., \& Stoner, L. (2014). The added value of study abroad: Fostering a global citizenry. Journal of Studies in International Education, 18(2), 141-161.

Taylor, E. (1998). The theory and practice of transformative learning: A critical review. Columbo: ERIC Clearinghouse on Adult Career and Vocational Education.

Taylor, E. (2008). Transformative learning theory. New Directions for Adult and Continuing Education, 119(Fall), 5-15.

Vogt, J. W. (1976). Wandering: Youth and travel behavior. Annals of Tourism Research, 4(1), 25-41. 